\title{
Awareness of bitewings among polish dentists
}

\section{Świadomość polskich lekarzy dentystów dotycząca stosowania zdjęć skrzydłowo-zgryzowych}

\author{
Katarzyna Denkiewicz ${ }^{1, A, B, D}$, Paweł Kalinowski2, ${ }^{2, E}$, Karolina Futyma ${ }^{3, B-D}$, Szymon Grzebyk ${ }^{3, B-D}$, Ingrid Różyło-Kalinowska ${ }^{1, A, E, F}$ \\ ${ }^{1}$ Independent Unit of Propaedeutics of Dental and Maxillofacial Radiology, Medical University of Lublin, Lublin, Poland \\ 2 Independent Unit of Epidemiology, Medical University of Lublin, Lublin, Poland \\ 3 Student Scientific Organization, Independent Unit of Propaedeutics of Dental and Maxillofacial Radiology, Medical University of Lublin, Lublin, Poland \\ A - research concept and design; $\mathrm{B}$ - collection and/or assembly of data; $\mathrm{C}$ - data analysis and interpretation; \\ $\mathrm{D}$ - writing the article; $\mathrm{E}$ - critical revision of the article; $\mathrm{F}$ - final approval of article
}

\section{Address for correspondence}

Katarzyna Denkiewicz

E-mail:denkiewicz.katarzyna@gmail.com

\section{Funding sources}

none declared

Conflict of interest

none declared

Received on March 23, 2017

Revised on April 28, 2017

Accepted on July 20, 2017
DOI

10.17219/dmp/75985

Copyright

○ 2017 by Wroclaw Medical University

and Polish Dental Society

This is an article distributed under the terms of the

Creative Commons Attribution Non-Commercial License

(http://creativecommons.org/licenses/by-nc-nd/4.0/)

\begin{abstract}
Background. Bitewing radiograph is one of three types of intraoral X-rays. It shows the crowns of upper and lower teeth at the same time and their marginal periodontium and it is more often used for the imaging of posterior teeth than incisors and canines. The main indication is the diagnosis of caries on the proximal surfaces, but also to evaluate the quality of dental fillings and the follow-up status of marginal periodontium.
\end{abstract}

Objectives. The aim of this study was to verify dentists'knowledge of this kind of imaging, the awareness of the indications for its use and the frequency of referral for such examinations.

Material and methods. A survey was conducted among 100 dentists working in Lublin and its surroundings. The questions included years of professional experience, possessing a specialization, frequency of use of bitewings in diagnosis and checking the knowledge of the radiograph's anatomy and indications. The data was statistically analyzed.

Results. Of 100 respondents, 57 people said that they had never referred any patient for a bitewing radiograph. As many as 79 doctors have not used such an examination in their workplace. There was neither a significant correlation between completed specialization and taking radiographs by dentists in their work place $(p=0.39)$, nor knowledge of the anatomy of bitewing radiographs ( $p=0.43)$. For 26 respondents, bitewing is synonymous with occlusal radiograph, and $92.3 \%$ of them have work experience of more than 10 years. As many as $58 \%$ of the respondents did not know the indications to perform bitewing examination.

Conclusions. The results of this survey show that dentists do not recommend bitewing examinations despite its obvious advantages. This may be due to the fact that many patients' dental caries are already very advanced, thus frequently producing inflammatory changes of the apical periodontium, which are visible on periapical radiographs, but not in bitewings.

Key words: survey, radiography, caries, bitewings

Słowa kluczowe: ankieta, zdjęcie rentgenowskie, próchnica, zdjęcie skrzydłowo-zgryzowe 
Tooth decay is one of the most common diseases in the world caused by bacteria. The challenge is to diagnose it properly, especially when it concerns early carious lesions on proximal surfaces. ${ }^{1,2}$ This is not easy in practice, because tooth caries develop slowly and do not produce any symptoms in the early stages., ${ }^{3,4}$ As carious lesions are often present on the proximal surfaces, it is recommended to perform not only a visual and clinical examination but also use bitewing X-rays. ${ }^{4-6}$ Other guidelines for taking such radiographs are examinations to determine if restorations are correct and to examine the periodontium., 1,2,-10

On a properly taken X-ray, the crowns of both upper and lower teeth and also their cervical areas are visible at the same time, but it is not possible to demonstrate root apices and periapical area ${ }^{7,11}$ (Fig. 1a-b). The combination of these two methods significantly improves the chances of proper diagnosis. ${ }^{4}$ If a dental caries is discovered early enough, it can easily be cured and in this way invasive treatment and excessive destruction of tooth hard tissue can probably be avoided. ${ }^{1,12}$

Radiography increases the sensitivity of the visual examination, which is why it is now considered the best performing test available for discovering dental caries on proximal surfaces. ${ }^{3}$ Bitewing X-rays are the best method in this kind of diagnosis; they have higher sensitivity and specificity compared to other techniques. ${ }^{5}$ This method is a very useful diagnostic tool used in everyday dental practice. $^{1,4,14}$

The aim of the paper is to verify dentists' knowledge of bitewing radiographs, the awareness of the indications for its use and the frequency of referral for such examinations.

\section{Material and methods}

The material consisted of questionnaires filled out by 100 dentists working in Lublin (Poland) and its surroundings. The questions took into consideration such factors as seniority, having a specialization and the frequency of using bitewing $\mathrm{X}$-rays in diagnosis. The questions also regarded the knowledge of radiographic anatomy and indications for using bitewing X-ray (Fig. 2).

The data collected was analyzed by means of STATISTICA software for Windows. The confidence level was $95 \%$ and the results with a probability value of $\mathrm{p}<0.05$ were regarded as significant.
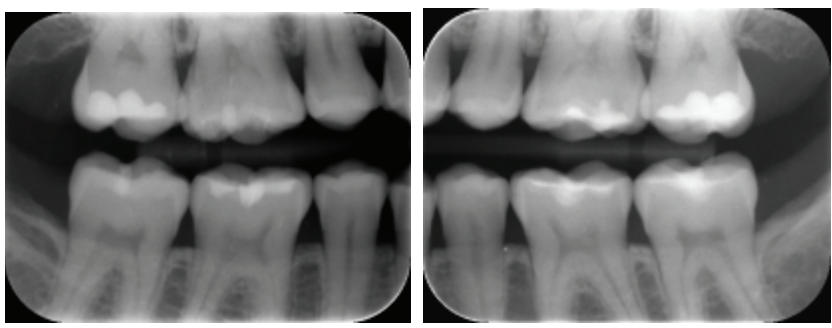

Fig. 1a-b. Examples of properly taken bitewing radiographs of right and left side

\section{OUESTIONNAIRE}

Dear Sir or Madam! We kindly ask you to complete the following questionnaire, which aims to gather information about bitewing images in dentistry. The questionnaire is completely anonymous, and its results will be used solely for scientific purposes in the framework of the Student Scientific Research Team at the Independent Unit of Propedeutics of Dental and Maxillofacial Radiology in Lublin.

Please mark your choice with the $X$ cross.

1. How long have you been working as a dentist?

$\Xi$ under 5 years

5 5-9 years

こ10-19 years

Ionger than 20 years

2. Do you have dental specialization?

EYes

I am atending the specialization course

No and I am not atending the specialization course

3. Do you prescribe bitewings?

$\Xi$ no, never

yes, several times a year

$\Xi$ yes, several times a month

yes, several times a week

4. Do you personally perform bitewings at your workplace?

$\Xi$ no, never

$\sim$ yes, several times a year

yes, several times a month

$\triangle$ yes, several times a week

5. Do you think bitewings are useful for diagnosing the following changes, and if so, which ones? (you can mark several responses)

caries on the proximal surfaces

$\Xi$ lesions in the maxillary sinus

$\checkmark$ inflammatory lesions of the apical periodontium

inflammatory lesions of the marginal periodontium

6. Do you think the terms "oclussal radiograph" and "bitewings" are synonymous?

¿yes

¿no

EI don't know

Thank you for completing the questionnaire!

Fig. 2. The survey questionnaire

\section{Results}

Out of the 100 dentists taking part in the survey, 57 said that they had never ordered a bitewing radiographic examination. No statistical differences were observed between the work experience of the surveyed and the frequency of referring patients for examination $(\mathrm{p}=0.41)$, as well as taking the radiographs themselves $(p=0.21)$. Seventy-nine doctors have never used bitewing X-ray in their workplace.

Forty-two percent of the dentists answered correctly about the structures visible in bitewings. There was a significant relationship between the period of work and knowledge of anatomy ( $\mathrm{p}=0.0001)$, and $58 \%$ of the people who took part in the survey did not know the specific indications for bitewing X-rays (Table 1).

For 26 of those surveyed, there is no difference between bitewing and occlusal X-rays and $92.3 \%$ of them had worked longer than 10 years. The period of professional experience was statistically correlated with correct distinction between the two types of radiographs $(\mathrm{p}=0.00003)$. Ten percent of doctors said that they did not know that there was a differ- 
Table 1. Detailed results of the survey on bitewing radiograph

\begin{tabular}{|l|c|c|c|cc|}
\multirow{2}{*}{$\begin{array}{c}\text { Years of professional } \\
\text { experience }\end{array}$} & \multicolumn{4}{|c|}{ Number of taken bitewing radiographs } & $\begin{array}{c}\text { Number of dentists, who have knowledge } \\
\text { of specific indications for bite-wing X-rays }\end{array}$ \\
\cline { 2 - 6 } Under 5 years & never & a few times a year & once a month & a few times a week & $63.9 \%$ \\
5 to 9 years & $75 \%$ & $16.7 \%$ & $8.3 \%$ & 0 & 0 \\
10 to 19 years & $92.9 \%$ & $7.1 \%$ & 0 & 0 & $16 \%$ \\
Over 20 years & $92 \%$ & 0 & $8 \%$ & $4 \%$ & $28 \%$ \\
\hline
\end{tabular}

ence between the aforementioned examinations. Among the dentists who responded properly, $45.3 \%$ had graduated no more than 5 years previously.

There was a statistically-proven dependency between having completed a dental specialization and referring patients for bitewing radiographs $(\mathrm{p}=0.007)$. Fifty-six percent of the surveyed doctors had never needed this kind of radiograph in their work. Thirty percent said that they had referred only a few patients per year for bitewings and $48.65 \%$ of them had completed a specialization course. There was no significant correlation between being a specialist in any dental field and the frequency of the respondents using the radiographs in their work place $(\mathrm{p}<0.39)$, nor in their knowledge of the anatomy for bitewing radiographs $(\mathrm{p}<0.43)$.

\section{Discussion}

The visibility of proximal dental caries on bitewing radiographs depends on many factors, such as the position of the tooth in the bone, advancement of the caries, settings of the X-ray tube, and the superposition of normal anatomical structures and artefacts. ${ }^{5}$ An example of an artefact is the so-called cervical burnout, which is located in a cervical region of premolar teeth and molar teeth and is due to uneven thickness of the tooth and thus unequal attenuation of the X-ray beam. ${ }^{1,14}$

The main issue with bitewing radiographs is that patients feel uncomfortable during the X-ray examination, especially taken by means of direct digital sensors - the so-called "solid" ones. ${ }^{6}$ This discomfort can be reduced by using conventional films or digital sensors that have a more ergonomic shape ${ }^{15}$ Attempts to improve the quality of X-ray images have led to the introduction of positioning devices which not only provide support to the X-ray detector but also provide the right angle of the X-ray beam. ${ }^{16}$

Still, there are large discrepancies in the frequency of usage of bitewing radiographs in different countries. In Sweden and Norway, bitewings are routinely taken along with a clinical examination in $90 \%$ of patients. ${ }^{4}$ In Poland, these X-rays are less common than periapical radiographs despite obvious indications. ${ }^{7}$ In Poland, the panoramic radiograph is a more popular method of radiographic diagnosis than bitewing X-ray. It has been proven that a single panoramic X-ray is less effective than bitewing radiograph in the diagnosis of dental caries and it is not indicated in the prophylaxis of caries. ${ }^{5}$
To improve the technique of bitewing radiography and also make it more popular, scientists are trying to minimize the radiation risk connected to its usage. It has been proven recently that lowering the peak voltage of the intraoral X-ray tube from $70 \mathrm{kV}$ to $60 \mathrm{kV}$ has no negative effects on the quality of the picture and, indirectly, on the follow-up of carious lesions ${ }^{17,18}$. It has also been proven that removal of soft tissues (especially the cheek) from the area where the X-ray beam is directed improves the quality of the X-ray of the bone and the contrast of the picture, thereby it increases the sensitivity of a bitewing. ${ }^{19}$

Removal of soft tissues seems to have a more important effect on the quality of the picture than the time extension of the X-ray exposure.

Bitewing X-ray is the second-best method in the followup of the degree of atrophy of alveolar bone of the jaw and alveolar part of the mandible, second only to periapical radiographs. Bitewings are more sensitive than clinical examination in the assessment of primary caries on approximal and occlusal surfaces. The sensitivity of approximal caries detection is 2 times higher in bitewing radiography compared to clinical diagnosis; in other words, half of approximal cavities are not diagnosed in clinical examination. ${ }^{18-20}$

One of the newest inventions is the technique of extraoral bitewing X-ray with a reduced dose of radiation for the patient. ${ }^{5}$ This type of X-ray is easier to be taken with patients with whom it is not possible to apply the standard method of taking bitewing X-rays; e.g. with patients with a strong gagging reflex, patients with spasms of the jaw muscles (trismus) or people with mental disorders. However, extraoral bitewing is not as effective in diagnosing tooth decay as intraoral bitewing radiograph. ${ }^{5,6}$

The results of the survey may stem from the fact that tooth decay is so advanced in Poland when reported and inflammatory changes of the apical periodontium are so extended that these force doctors to use periapical radiograph, which additionally shows this area, unlike bitewings.

\section{Conclusions}

Despite many advantages, the results of the survey show that doctors do not prescribe bitewing X-ray. One can come to the conclusion that the longer the seniority of the dentists, the more frequently they tend to forget about the qualities and indications in ordering bitewing radiographs. 


\section{References}

1. Secgin CK, Gulsahi A, Arhun N. Diagnostic challenge: Instances mimicking a proximal carious lesion detected by bitewing radiography. OHMD, 2016;15:1-5.

2. Tan PLB, Evans RW, Morgan MV. Caries, bitewings, and treatment decisions. Austral Dent J. 2002;47:138-141.

3. Bizhand M, Wollenweber W, Singh-Husgen P, Danesh G, Zimmer S. Pen-type laser fluorescence device versus bitewing radiographs for caries detection on approximal surfaces. Head Face Med. 2016;12:17.

4. Hietala-Lenkkeri AM, Tolvanen M, Alanen P, Pienihakkinen K. The additional information of bitewing radiographs in the detection of established or severe dentinal decay in 14-year olds: A cross-sectional study in low-caries population. Sci World J. 2014: ID 175358.

5. Kamburoğlu K, Kolsuz E, Murat S, Yuksel S, Ozen T. Proximal caries detection accuracy using intraoral bitewing radiography, extraoral bitewing radiography and panoramic radiography. Dentomaxillofac Radiol. 2012;41:450-459.

6. Abdinian M, Razavi MS, Faghihian R, Samety AA, Faghihian E. Accuracy of digital bitewing radiography versus different views of digital panoramic radiography for detection of proximal caries. J Dent. 2015;43:290-297.

7. Różyło-Kalinowska I, Różyło TK. Contemporary dental radiology. Czelej, Lublin, 2015:90-91 [in Polish].

8. Whaites $E$, Drage N. Essentials of dental radiography and radiology. Elsevier, London, 2013:205-208.

9. Różyło TK, Różyło-Kalinowska I. Dental radiology. PZWL, Warszawa, 2007:12-90 [in Polish].

10. Pruszyński B, Cieszanowski A. Diagnostic imaging RTG, TK, USG, MR. PZWL, Warszawa, 2014:173-174 [in Polish].

11. Silva RF, Franco A, Picoli FF, Rodrigues LG, Gomes RR. Dental human identification using bitewing radiographs: A case report. Eur J Forensic Sci. 2001;3:31-33.

12. Mepparambath R, Bhat SS, Hedge KS, Anjana G, Sunil M, Mathew S. Comparison of proximal caries detection in primary teeth between laser fluorescence and bitewing radiography: An in vivo study. Int J Clin Pediatr Dent. 2014;7:163-167.

13. Taylor GK, Macpherson LM. An investigation into the use of bitewing radiography in children in Greter Glasgow. Br Dent J. 2004;196:563-568.

14. Kunisch J, Paster FA, Bucher K, Hickel R, Heinrich-Weltzen R. Frequency of non-carious triangular-shaped radiolucencies on bitewing radiographs. Dentomaillofac Radiol. 2008;37:23-27.

15. Jørgensen PM, Wenzel A. Patient discomfort in bitewing examination with film and four digital receptors. Dentomaxillofac Radiol. 2012;41:323-327.

16. Safi Y, Esmaeelinejad M, Vasegh Z, et al. Utility of a newly designed film holder for premolar bitewing radiography. J Clin Diagn Res. 2015;9:4-7.

17. Hellén-Halme K, Nillson M. The effects on absorbed dose distribution in intraoral X-ray imaging when using tube voltages of 60 and 70 kV for bitewing imaging. J Oral Maxillofac Res. 2013;4:e2.

18. Abesi F, Mirshekar A, Mondi E, et al. Diagnostic accuracy of digital and conventional radiography in the detection of non-cavitated approximal dental caries. Iran J Radiol. 2012;9:17-21.

19. Safi Y, Kadkhodazadeh M, Safai P, Esmaeelinejad M, Shamloo N. Evaluation of alveolar crest bone loss via premolar bitewing radiographs: presentation of a new method. J Periodontal Implant Sci. 2014;44:222-226.

20. Kajka-Hawryluk K, Furmaniak K, Gromak-Zaremba J, Szopiński K. Bitewing radiographs in contemporary pediatric dentistry. Nowa Stomatol. 2015;20:2,73-80 [in Polish]. 